\title{
Methods and Products for the Conservation of Vandalized Urban Art Murals
}

\author{
Andrea Macchia ${ }^{1}$, Margarida Castro ${ }^{2}$, Claudia Curbelo ${ }^{1}$, Laura Rivaroli ${ }^{1}$, Sara Capriotti ${ }^{1}$, Eduarda Vieira ${ }^{2}$ (D), \\ Patrícia Moreira ${ }^{3}$, Silvestro Antonio Ruffolo ${ }^{4}$ and Mauro Francesco La Russa ${ }^{4}$ *
}

1 Youth in Conservation of Cultural Heritage (YOCOCU), 00185 Rome, Italy; info@yococu.com (A.M.); info@yocou.it (C.C.); laura_rivaroli@yahoo.it (L.R.); saracapriotti@yahoo.it (S.C.)

2 Universidade Católica Portuguesa, School of Arts, CITAR, Research Centre for Science and Technology of Arts, 4169-005 Porto, Portugal; yococu.yococu@gmail.com (M.C.); evieira@porto.ucp.pt (E.V.)

3 Universidade Católica Portuguesa, School of Arts, Research Centre for Science and Technology of Arts, CITAR and Faculty of Biotechnology, CBQF, Research Centre of Biotechnology and Fine Chemistry, 4169-005 Porto, Portugal; prmoreira@porto.ucp.pt

4 DiBEST-Dipartimento di Biologia, Ecologia e Scienze della Terra, University of Calabria, 87036 Rende, Italy; silvestro.ruffolo@unical.it

* Correspondence: mauro.larussa@unical.it

check for

updates

Citation: Macchia, A.; Castro, M.; Curbelo, C.; Rivaroli, L.; Capriotti, S.; Vieira, E.; Moreira, P.; Ruffolo, S.A.;

La Russa, M.F. Methods and Products for the Conservation of Vandalized Urban Art Murals. Coatings 2021, 11, 1304. https://doi.org/10.3390/ coatings11111304

Academic Editor:

Ioannis Karapanagiotis

Received: 20 August 2021

Accepted: 25 October 2021

Published: 27 October 2021

Publisher's Note: MDPI stays neutral with regard to jurisdictional claims in published maps and institutional affiliations.

Copyright: (c) 2021 by the authors. Licensee MDPI, Basel, Switzerland. This article is an open access article distributed under the terms and conditions of the Creative Commons Attribution (CC BY) license (https:// creativecommons.org/licenses/by/ $4.0 /)$.

\begin{abstract}
The possibility of contemporary mural paintings to be "tagged" by vandals, with spray and/or markers, represents a serious problem for the conservation of urban art. The present study aims to define the applicability of a protective coating on murals' surface to preserve them against vandalism. The research has been focused on anti-graffiti products currently used in the field of cultural heritage conservation. These products represent an optimum start point to preserve mural artwork from vandal actions. The commercially available anti-graffiti products have been compared with an innovative product, PRO-ART, specifically formulated by YOCOCU in collaboration with Pelicoat, for the conservation of murals. At the same time, it has tested the cleaning of contemporary murals by using different mixtures of solvents and surfactants. The experimentations have been carried out on external walls, followed by the conducting of in situ tests (application tests, empirical evaluations and colorimetric analysis), as well as laboratory investigations (contact angle and optical/electronic microscopy).
\end{abstract}

Keywords: conservation urban art; murals; coating; protective layer; cleaning

\section{Introduction}

Public art in the urban environment, particularly murals, is made with community engagement; these are projects aimed to promote community identity and to counter social and urban degradation [1,2]. Murals are often made on the facades of buildings which are selected together with civic institutions and the property owners of the wall. In spite of the tangible social and cultural significance mural paintings, as urban art expressions, face the threat of impermanence as a unique heritage artwork [3]. Climatic weathering, the nature of materials and vandalism are the main causes of degradation [4,5]. In particular, vandalism is due both to the lack of appreciation of the artwork or for its social history, and the loss of cultural integrity through changes in social tastes, as well as authorities' ambivalence in defining murals as community art. This has contributed to the need to sustain and to preserve street murals [6]. Currently, the debate is mainly limited to the theoretical aspects with regard to the question of whether it is right or not to preserve a mural. The crucial point has nothing to do with the technical aspects of materials [6]. The conservation of street art is a topic of great dispute which exploits the limits of ethics and sets new challenging questions for value assessment and decision making [7,8].

An urban mural painting is a complex unit to study and to preserve [9]; this creates a new scenario that imposes specific considerations regarding the study, that being the 
treatment and the preservation of particular artworks. On the other hand, the possibility of the artwork being "tagged" by vandals, with spray and/or markers, is a serious problem considering that any cleaning system, both mechanic and chemical, can interact with the underlying surface. The chemical cleaning is more difficult to apply because the act of vandalism is often performed with varnish spray, which is chemically similar to those used to make the mural, and thereby risks removing both the vandal's and the original artist's varnishes at the same time. Finally, the vandal's varnish solvent could attach to the artist's varnish, interacting with the top layers and forming an admixture of varnishes. Vandalism the public art is certainly a risk, but it could be limited by the application of an anti-vandalism and preservation coating systems.

In the last years, a wide range of anti-graffiti coatings have become available and they are divided into two main categories: sacrificial and permanent [10-12]. A sacrificial coating is a reversible protective layer system, designed to be easily removed along with the graffiti or other soiling materials. The other type of coating is able to prevent the adhesion of the vandal's content on the treated surface.

Even if several protective coating (anti-graffiti) products are normally used to facilitate the graffiti removal from walls [13], in this paper, we focused our attention on the effectiveness of these products to preserve the murals. The research has been conducted on well-known anti-graffiti products available in the marketplace. These products are characterized by low chromatic alteration of the treated surface and high durability $[14,15]$, so they represent an optimum starting point to define materials to perverse mural artwork against vandalism. The main problem is the substrate, usually represented by porous material with different chemical-physical condition with respect to mural artwork [9]; for this reason, a methodology to apply these anti-graffiti with few drawbacks is needed.

Anti-graffiti-based products have been tested on fluorinated polymers and waxes. These materials have been compared with an innovative product, PRO-ART, formulated by YOCOCU in collaboration with the Pelicoat Italia s.r.l. (Rome, Italy).

Currently, on the horizon of green chemistry products is the substitution of toxic products, which have long atmospheric lifetimes, by eco-friendly and sustainable alternative products with low VOC's [16-18]; this represents a greater awareness of environmental preservation, the health of the operator and the impact on the mural artwork [19].

This study describes some of the results of collaborative research between YOCOCU APS (YOuth in COnservation of CUltural Heritage APS, Rome, Italy) and M.U.Ro, (Museo Urbano Roma, Rome, Italy) started in 2014, with the aim of developing new methods and materials to be used for street art conservation.

\section{Materials and Methods}

\subsection{Sample Preparation}

Tests were performed on an outdoor south-facing wall (Rome, October 2020). It was made of concrete coated with an industrial paint. Several samples with the same size were made by using a circular stencil (diameter $7 \mathrm{~cm}$ ) and different paints were applied (Table 1). These paints have been selected because of their colour that gives a great contrast with the vandal's layer (which is black); moreover, they are considered the most commonly used for the purpose of urban art.

\subsubsection{Protective Coatings}

The first aim of the study was to assess the suitability of several protective coatings that are used in the cultural heritage sector for their effectiveness in the conservation of urban art murals. Four protective coatings were selected and described in Table 2, all of them water-based formulations, and then, they cannot solubilize the substrate. It is important to underline that AG09W, IMAR, and PROTECT IT 100/HBG are commonly used for building heritage, while PRO-ART is specifically developed for urban art murals by YOCOCU during the M.U.Ro project. All products were applied by brush. 
Table 1. List of paints.

\begin{tabular}{|c|c|c|c|c|c|c|}
\hline Acronyms & Products & Application & RAL Color Standard & Binder & Thinner & Color \\
\hline MNT94 & $\begin{array}{c}\text { Montana } 94 \\
\text { (MONTANA COLORS } \\
\text { S.L. Barcelona, Spain) }\end{array}$ & spray & $\begin{array}{l}\text { Bourdeux red } \\
\text { RV-3004 }\end{array}$ & $\begin{array}{l}\text { Modified } \\
\text { alkyd resins }\end{array}$ & Ethyl acetate & \\
\hline IVAS SP & $\begin{array}{l}\text { Ivas Superquarz Plus } \\
\text { (IVAS, San Mauro } \\
\text { Pascoli (FC), Italy) }\end{array}$ & brush & RAL-3004 & $\begin{array}{l}\text { Acryl- } \\
\text { siloxane } \\
\text { resin }\end{array}$ & Water & \\
\hline LOOP & $\begin{array}{l}\text { Loop (ITALG.E.T.E, } \\
\text { Morimondo MI, Italy) }\end{array}$ & spray & Bristol 143 & Acrylic resin & Ethyl acetate & \\
\hline MNT WB & $\begin{array}{l}\text { Montana Water Based } \\
\text { (MONTANA COLORS } \\
\text { S.L. Barcelona, Spain) }\end{array}$ & spray & Carmine W-3004 & $\begin{array}{c}\text { Modified } \\
\text { Polyurethane }\end{array}$ & Water/Alcohols & \\
\hline IVAS SA & $\begin{array}{c}\text { Ivas Idromatt (IVAS, } \\
\text { San Mauro Pascoli } \\
\text { (FC), Italy) }\end{array}$ & brush & RAL-4010 & Acrylic resin & Water & \\
\hline
\end{tabular}

Table 2. List of protective coatings.

\begin{tabular}{cccc}
\hline Acronym & Commercial Name & Main Component & Manufactured \\
KEIM & AG09W & Microcrystalline waxes & $\begin{array}{c}\text { KEIM, KEIMFARBEN GMBH, } \\
\text { Diedorf, Germany }\end{array}$ \\
\hline IMAR & Antigraffiti I.M.A.R & Wax and fluoropolymer & I.M.A.R. Italia SRL, Rome, Italy \\
\hline IBIX & Protect IT 100/HBG & Fluorinated polymer & IBIX Biocare Lugo (RA), Italy \\
\hline PRO-ART & PRO-ART & Fluorinated acrylic polymer & YOCOCU/Pelicoat, Rome, Italy \\
\hline
\end{tabular}

A simulation of an act of vandalism was performed on specimens (coated and uncoated by anti-graffiti) by using a MTN94 black aerosol paint, the same as paint A (see Table 1), except for the color. In order to check the distribution of the coating on the surface and their possible penetration, $\mathrm{TiO}_{2}$ and $\mathrm{ZnO}$ have been added $(5 \% w / w)$ to the coatings as a contrast agent for electronic microscopy observations.

\subsubsection{Chemical Cleaning Tests}

The efficacy of several mixtures of solvents and surfactants on samples (Figure 1) were tested. The following materials were used: water, ethanol, acetone, DBE-LVP (a mixture of dimethyl adipate/dimethyl glutarate, having a low vapor pressure), 2methyltetrahydrofuran (2-MeTHF), which represents a greener alternative to common organic solvents [20], Tween 20 (a non-ionic surfactant) and sodium laureth sulfate (an anionic surfactant). The cleaning tests have been carried out by wiping the surfaces with a swab containing the mixture, and making visual inspections by evaluating empirical parameters such as the progressive coloring of the swab, how many strokes were needed to start removing the black layer, and how much solvent was needed (details are reported in Supplementary Materials).

The mixtures are based on a water + ethanol mixture, while the addition of $2 \%$ detergent permits surface wettability and the dissolution of fats on the surface. The other solvents were selected for their ability to remove several aerosol paints, while presenting low toxicity and little on the environment. The compositions are summarized in Table 3. 


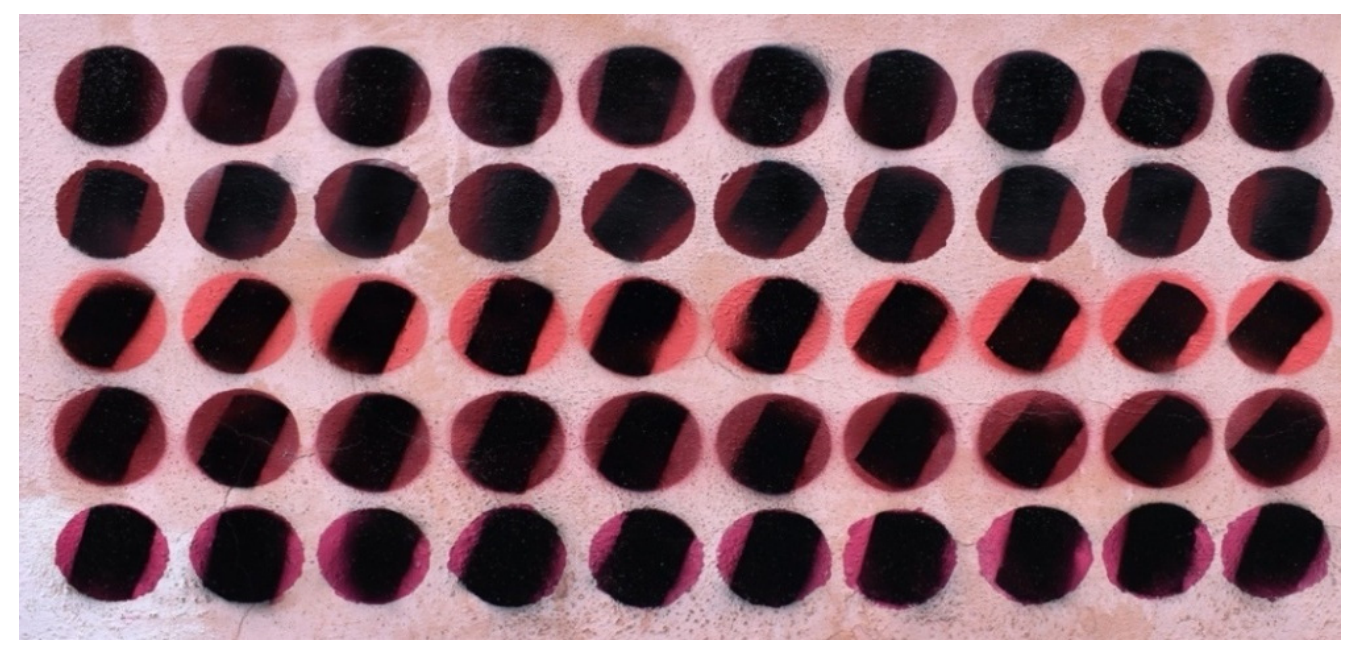

Figure 1. Vandalism carried out on selected specimens for cleaning tests.

Table 3. Solutions used in the research.

\begin{tabular}{cc}
\hline Mixture ID & Composition \\
\hline 1 & Ethanol/2-MeTHF/Water + Tween $20(2 \%)(55 / 10 / 35)$ \\
2 & Ethanol/Water + Tween $20(2 \%)(70 / 30)$ \\
3 & Ethanol/Water + SDS $(2 \%)(70 / 30)$ \\
4 & Ethanol/Acetone $(70 / 30)$ \\
6 & Ethanol/DBE-LVP/Water + Tween $20(2 \%)(70 / 20 / 10)$ \\
7 & Ethanol/2-MeTHF/Water + Tween $20(2 \%)(50 / 20 / 30)$ \\
8 & DBE-LVP/2-MeTHF/Ethanol/Water + Tween $20(2 \%)(10 / 10 / 70 / 10)$ \\
\hline
\end{tabular}

\subsection{Instrumental Techniques}

Analytical techniques have been adopted for the investigation of the protective coatings and to observe the features of the surfaces.

A contact angle has been observed to assess the capability of wetting the painted surface, and the compatibility of the anti-graffiti coating with the paint layer. Drops of each coating solution were put on the surface of one microscope slide pre-coated with the several paints. The images of the contact angle were collected by a digital camera.

Colorimetric tests have been carried out by using a NY 810 3nh spectrophotometer to assess chromatic variations induced by anti-graffiti products on the painted surface. Chromatic values are reported in the CIE $L^{*} a^{*} b^{*}$ space, $L^{*}$ is the lightness/darkness coordinate, $a^{*}$ the red/green coordinate $\left(+a^{*}\right.$ indicating red and $-a^{*}$ green) and $b^{*}$ the yellow/blue coordinate $\left(+b^{*}\right.$ indicating yellow and $-b^{*}$ blue). The chromatic alterations $(\Delta E)$ induced on the surface by the different products were analysed used the equation:

$$
\Delta E=\sqrt{\left(\Delta L^{*}\right)^{2}+\left(\Delta a^{*}\right)^{2}+\left(\Delta b^{*}\right)^{2}}
$$

where $\Delta L^{*}, \Delta a^{*}, \Delta b^{*}$ are the difference of each coordinate between two set of measures. This assessment was performed before coating, after the coating application, and after four months.

Optical microscopy (OM) was used for superficial and stratigraphic observation of the surface, penetration and the homogeneity checks of the protective film, and a Zeiss Axiolab microscope (Oberkochen, Germany) was used for this purpose.

Scanning electronic microscopy coupled with microanalysis (SEM-EDS) was carried out by using a 360 Cambridge Instruments Stereoscan (Cambridge Instrument Company, London, UK), with observations in secondary electrons (SE) and backscattered electrons (BSE) modes (accelerating voltage $20 \mathrm{kV}$, beam current: $0.2 \mathrm{~mA}$ ). 


\section{Results and Discussion}

\subsection{Protective Coatings}

The protective efficacy was evaluated using the following parameters: applicability, wettability (contact angle), micromorphology of the coatings (optical and electron microscopy), and visual and instrumental evaluation of the alteration (colorimetric analysis). The applicability is a qualitative test aimed to understand how it is easy to apply the product in terms of spreadability on the surface and the homogeneity achieved. A single operator applied all products on all paints, and the results are summarized in Table 4 . The test can be biased by the operator's skills, but it can be considered relevant for comparing the performances of all tested products. PRO-ART and KEIM coatings were the most suitable for all the paints tested. Coatings on Ivas SP painted surfaces showed a poor performance due to its rapid absorption into the substrate, due to the high porosity of the paint. The other two coating products (IMAR and IBIX) showed similar results.

Table 4. Applicability of protective coatings over chromatic layers. Scale from $+($ bad $)$ to +++ (very good).

\begin{tabular}{ccccc}
\hline \multirow{2}{*}{ Paints } & \multicolumn{4}{c}{ Protective Coatings } \\
& IMAR & PRO-ART & IBIX & KEIM \\
\hline Montana 94 & + & ++ & + & ++ \\
Ivas SP & ++ & + & ++ & + \\
Loop & + & +++ & + & +++ \\
Montana WB & + & ++ & + & +++ \\
Ivas SA & + & +++ & + & ++ \\
\hline
\end{tabular}

Figure 2a shows the stratigraphy of a MTN94 ink as paint, vandalized and without any protective coating. It is clear that the black layer penetrates into the red layer, and this occurs because the solvent of the black paint can dissolve the underlying paint. In Figure 2b the MTN94 paint coated with KEIM is shown; here penetration did not take place because of the protective layer. Figure $2 \mathrm{c}$ illustrates the following sequence: IVAS SP as paint, PRO-ART as coating, and the black layer on the top. In this case there is a visible penetration of the black layer into the red one; this is due to the porosity of the substrate, which leads to the penetration of the coating as well. SEM EDS analysis was carried out on samples treated with coatings containing $\mathrm{TiO}_{2}$ and $\mathrm{ZnO}$ (materials which have a great contrast in BSE mode), in order to assess the location and distribution of the coatings within the sample. Results revealed a certain penetration of the coatings when the vandal layer is applied. In Figure 3a, a layer containing Ti is visible on the top, while in Figure $3 b$ such a layer is less visible. This fact can be due to the solvent effect exerted by the thinner on the black paint. Generally, there was found a good homogeneity of the coating detected by Ti and Zn mapping (Figure 3c).

The behavior of Ivas SP toward the coating wettability was also verified by the contact angle. Figure 4 reports the images of wettability of the different anti-graffiti applied to the surfaces of the slides painted with Ivas SP paint that allows the comparison of all coatings. One drop of any coating was instantly absorbed by Ivas SP, but a second drop had a bigger contact angle, particularly the PRO-ART coating.

The lower wettability is due to the formation of a hydrophobic layer on the surface. This could represent a drawback, since if a hydrophobic surface is created a second layer of coating (which is water-based) is hardly applicable in the short-term. 

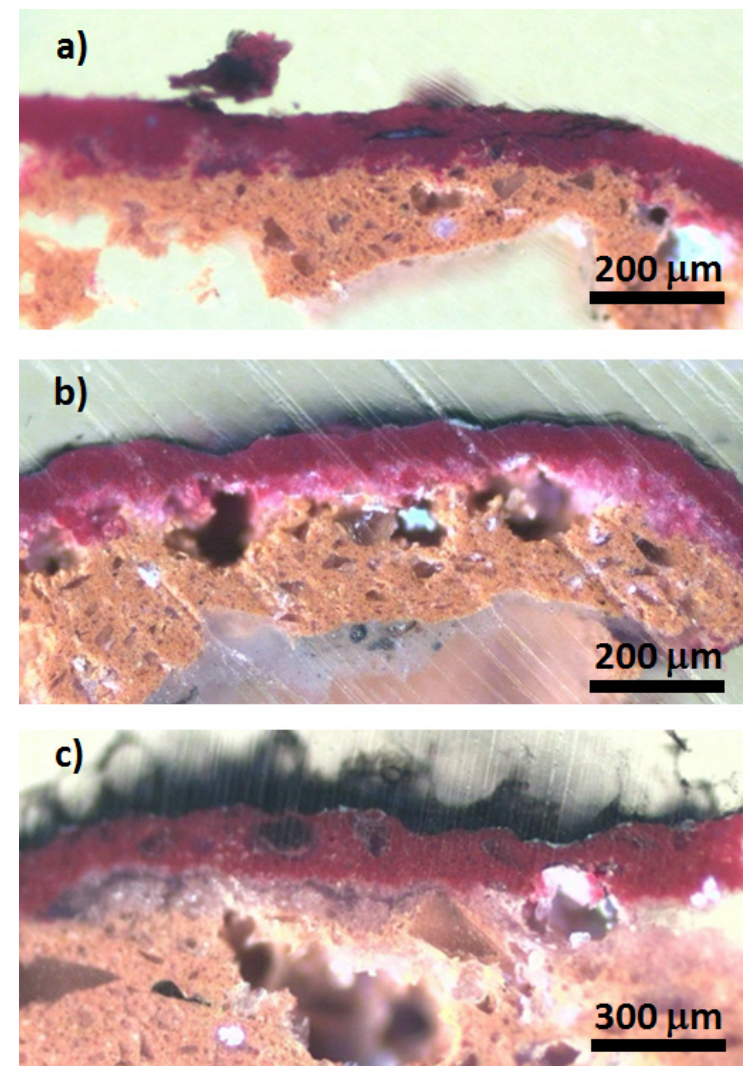

Figure 2. Microscopy images of: (a) MTN94 paint—vandal layer; (b) MTN94 paint-KEIM coatingvandal layer; (c) IVAS SP paint-RO-ART coating—vandal layer.
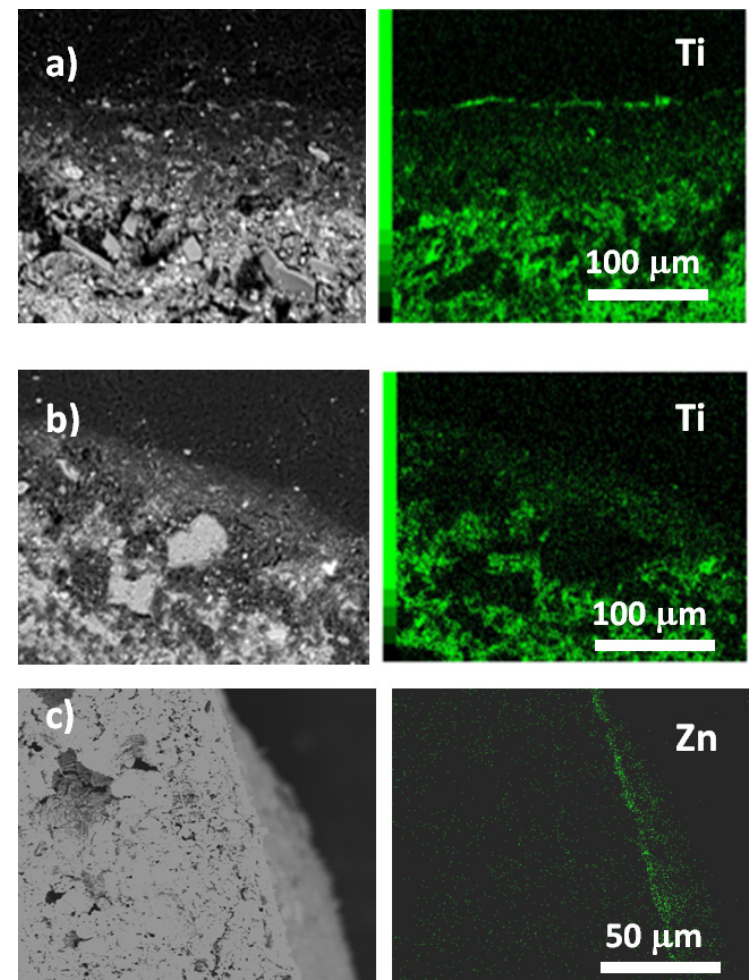

Figure 3. SEM-EDS images (SE/BSE on the left and EDS elemental map on the right) of: (a) MTN 94 coated with Pro-Art $\left(\mathrm{TiO}_{2}\right)$, it is visible a continuous layer of $\mathrm{TiO}_{2}$ on the top (b) MTN 94 coated with Pro-Art $\left(\mathrm{TiO}_{2}\right)$ with vandal layer, there is not any visible layer of $\mathrm{TiO}_{2}$ on the top (c) MTN 94 coated with PRO-ART, the Zn map suggests a homogeneous distribution of the coating on the surface. 

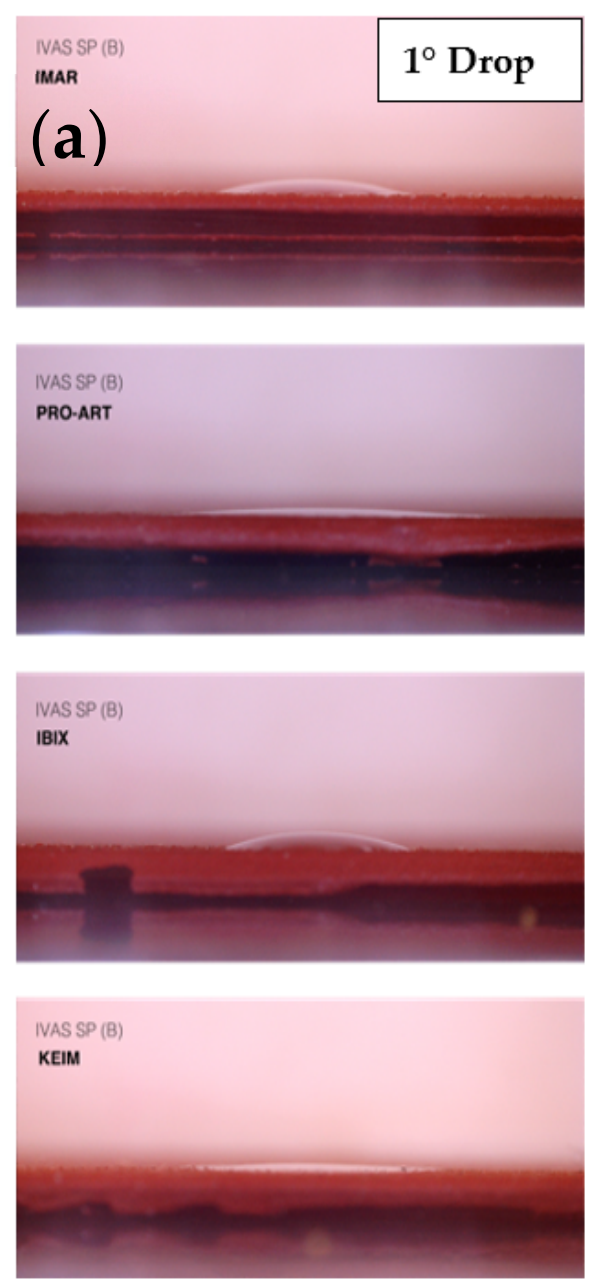

Figure 4. Coatings wetting test on Ivas SP: (a) first coating drop and (b) second coating drop.

Colorimetric measures were performed after application of the coatings and again after four months. Figure 5 shows the differences between the two sets of measurements. Good performance was achieved by IMAR on MTN94 and on Ivas SA, but for the other paints, greater colorimetric differences were detected. The best performances were shown by PRO-ART on MTN94, Ivas SP and MTN WB, while poor performance was demonstrated on LOOP. IBIX does not show a good performance on any paint, while KEIM produces the greatest colorimetric difference.

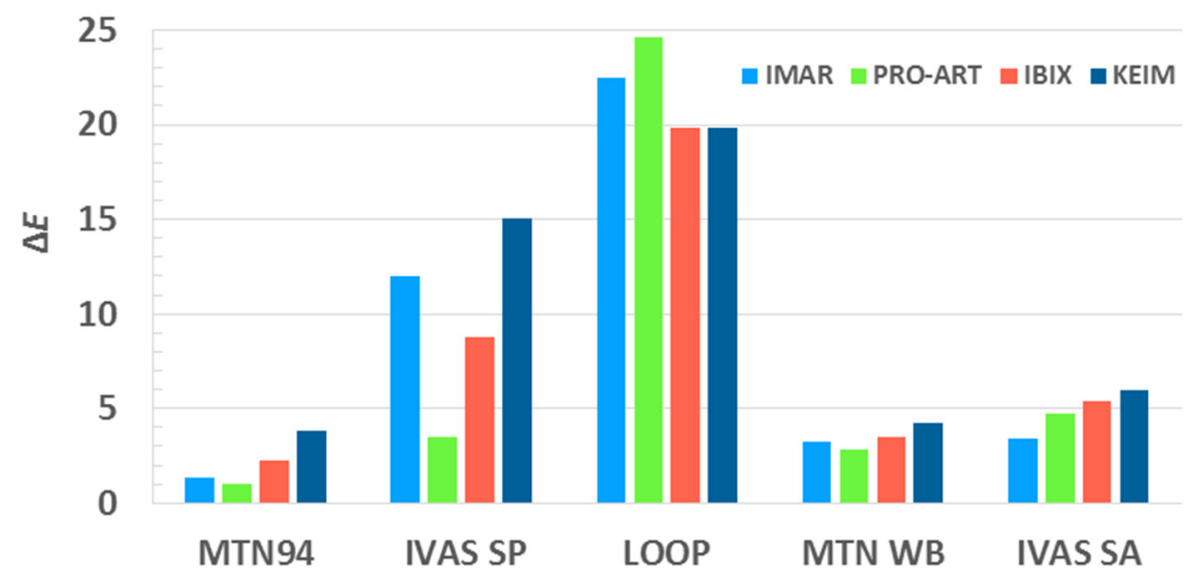

Figure 5. Colorimetric differences between paints four months after the coatings were applied. 
Figure 6 illustrates the chromatic difference values (as an average of three measurements) of all paints coated with each anti-graffiti substance after four months of aging. The results suggest that PRO-ART is the most suitable coating for all paints.

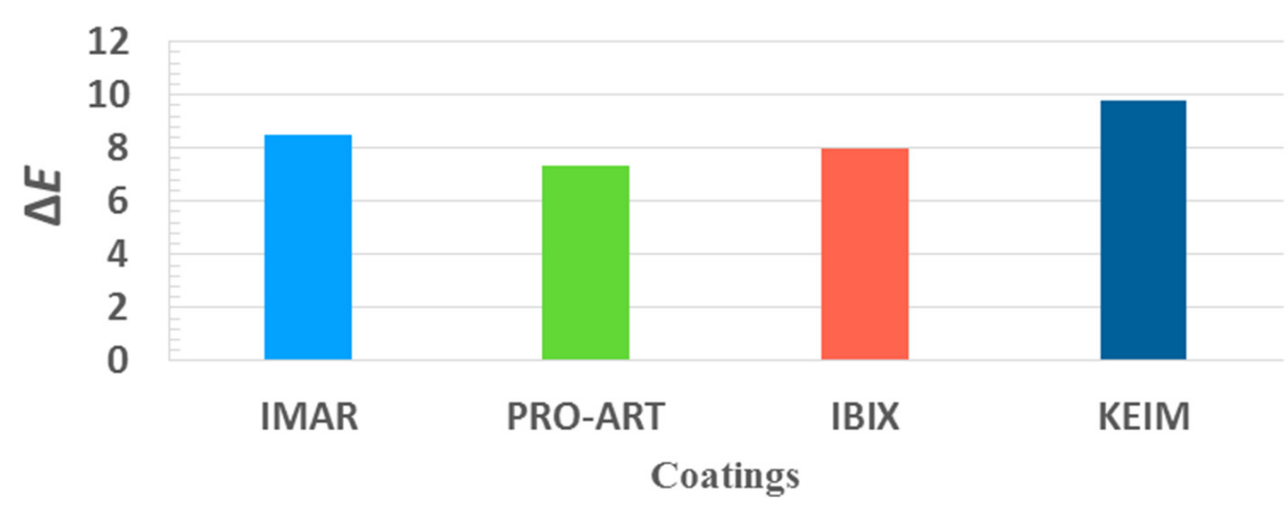

Figure 6. Colorimetric measures averaged for all paints four months after the application of coatings.

\subsection{Chemical Cleaning}

All chemical mixtures were tested on the vandalized paints (Figure 7). Results are reported in Tables S1-S4 and summarized in Table 5 and in Figure 8.

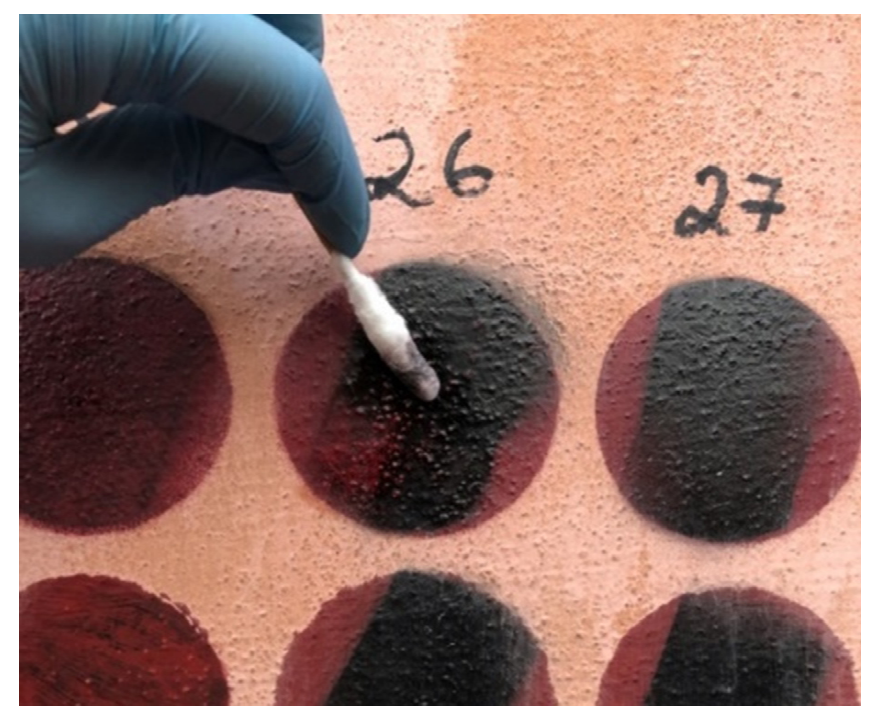

Figure 7. Cleaning test carried out by wiping the vandalized surface with a mixture of solvents.

Table 5. Solubility tests on vandalism removal over selected paints.

\begin{tabular}{ccccccccc}
\hline \multirow{2}{*}{ Paint } & $\mathbf{1}$ & $\mathbf{2}$ & $\mathbf{3}$ & $\mathbf{4}$ & $\mathbf{5}$ & $\mathbf{6}$ & $\mathbf{7}$ & $\mathbf{8}$ \\
\hline MTN94 & - & - & - & $\checkmark$ & - & $\times$ & $\checkmark$ & - \\
IVAS SP & - & - & - & - & - & $\times$ & - & - \\
LOOP & $\times$ & $\times$ & - & - & - & $\times$ & $\times$ & - \\
MNT WB & - & - & - & $\checkmark$ & $\times$ & - & $\times$ & - \\
IVAS SA & $\times$ & - & - & $\times$ & $\times$ & - & $\times$ & - \\
\hline
\end{tabular}

Note: $\checkmark$-solutions that presented better results. $\times$-solutions that presented good results but need control in cleaning. 

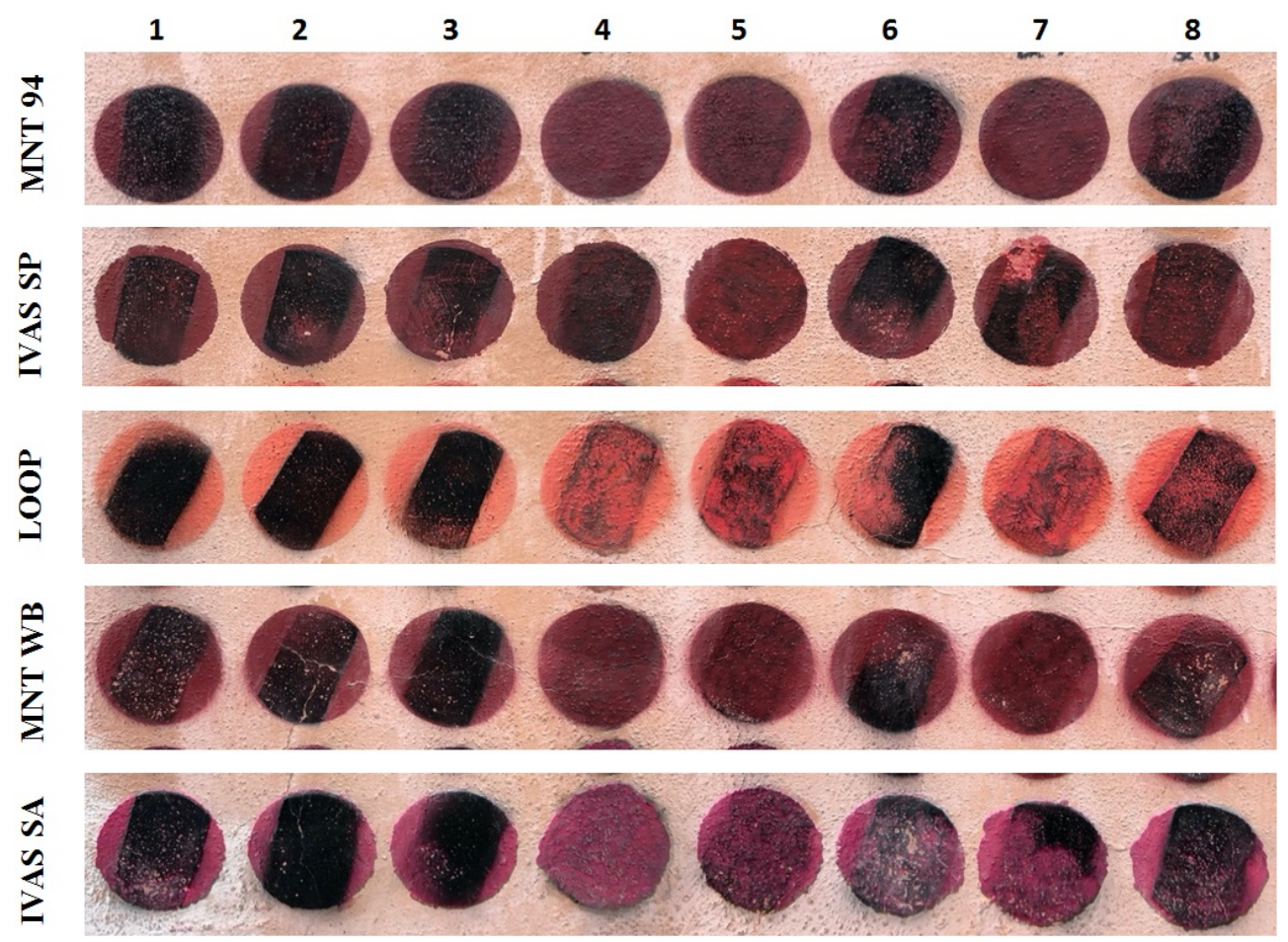

Figure 8. Cleaning tests performed on vandalized specimens.

For surfaces painted with Montana 94, mixtures 6 and 7 showed the better results. The solubilization of the vandal paint by the mixture 4 was easy and quick, and it did not remove the underlying pictorial layer. However, the rapid evaporation of acetone produced a whitish appearance. Mixture 6 showed a quick solubilization the vandalized chemical without showing any chromatic alteration; however, the embossing belonging to the substrate, was removed. Mixture 7 showed a poor control of the cleaning of thin layers of vandalism, so its use would be recommended only for thicker vandalism layers.

For surface painted with Ivas SP, solubility tests did not allow a choice of a solution suitable for a controlled removal of the black layer. Mixtures 4, 6 and 7 induced a rapid solubilization of the vandalism varnish, but the removal of the Ivas SP paint as well. Mixtures 1, 2 and 3 partially removed Ivas SP paint together with the vandalism layer.

Regarding surfaces painted with LOOP, for thin vandalism layers, solutions 1,2, and 6 achieved a good performance, and for thick vandalism layers, mixture number 7 was the best one. Mixtures 1, 2 and 6 had shown a rather poor performance, although they did not affect the underlying color. Mixture 7 had the fastest action, but it should be used only for thick vandalism layers, since it would quickly dissolve the underlying layer.

The Montana water-based paint, when compared to MTN94, showed similar behavior toward mixture 4, and an easy and quick solubilization of the vandal paint occurred; unfortunately, it also induced the formation of a whitish surface, which resulted from the rapid evaporation of the acetone, together with the removal of some embossments. Solution 5 was slightly more aggressive than the previous one because it rapidly removed the embossments from the underlying surface, but it was verified that with the rolling cleaning technique it was possible to avoid this issue. Mixture 7 effectively removed the thick vandal layers, but partially dissolved the substrate as well.

For thin layers of vandalism on Ivas Idromatt, mixture 1 showed a controlled and homogeneous cleaning of the vandal's chemical on smooth surfaces. Mixture 4 showed quick results, while mixture 5 was slightly more aggressive, but by using the rolling cleaning technique, it was possible to avoid the alteration of the chromatic layer. With mixture 7 , the rolling cleaning technique should also be used to avoid dissolution of the underlying layer. 


\section{Conclusions}

Urban rt conservation is a complex matter that requires real expertise and the knowledge of several professionals: artists, restorers, conservation scientists, and other stakeholders. The context of the artwork will always be relevant in conservation of urban art, as well different perspectives regarding which is the best approach to be adopted. The research on protective coatings, together with the testing of cleaning mixtures on vandalism, has been aimed at developing new methods for the conservation of urban art murals.

Microscopic observations suggest that anti-graffiti applications can avoid the penetration of the vandal layer into the substrate, although significant color variations were detected by colorimetric analyses. Higher values were revealed as LOOP paint was coated with anti-graffiti. PRO-ART coating seems to be the best product in terms of color changing.

Several mixtures of solvents have been tested as cleaning agents for the removal of the vandal's black paint from painted surfaces. Results suggested that there is not a single mixture suitable for all of the tested materials. The mixtures worked effectively on alkyd binder paints (MTN94 and NBQ Pro) and in in modified polyurethane binder paints (MTN WB). Although there is not any "universal" mixture suitable for all paints, a combination DBE-LVP/2-methyltetrahydrofuran/ethanol/water 1/1/1/1 + Tween $20(2 \%)$ seems to have an overall good performance. For future work, it would be interesting to apply these mixtures on semi-rigid supports, such as hydrogels, as this could be a more uniform and controlled cleaning procedure. Moreover, the assessment of the performance of cleaning and protective treatments in situations where the inhomogeneity of the surface is present, such as with cracks.

Supplementary Materials: The following are available online at https: / www.mdpi.com/article / 10.3390/coatings11111304/s1, Table S1: Solubility tests on vandalized specimens with Montana 94, Table S2: Solubility tests on vandalized specimens with IVAS SP, Table S3: Solubility tests on vandalized specimens with Loop, Table S4: Solubility tests on vandalized specimens with Montana Water Base.

Author Contributions: Conceptualization, A.M., L.R. and S.A.R.; methodology, A.M., M.C., E.V., P.M. and S.A.R.; investigation, A.M., M.C., C.C., L.R. and S.C.; resources, M.F.L.R., A.M. and E.V.; writingoriginal draft preparation, A.M., M.C., C.C., L.R. and S.C.; writing—review and editing, E.V., P.M., S.A.R. and M.F.L.R. All authors have read and agreed to the published version of the manuscript.

Funding: This research received no external funding.

Institutional Review Board Statement: Not applicable.

Informed Consent Statement: Not applicable.

Data Availability Statement: Not applicable.

Conflicts of Interest: The authors declare no conflict of interest.

\section{References}

1. Iveson, K. The wars on graffiti and the new military urbanism. City 2010, 14, 115-134. [CrossRef]

2. McAuliffe, C.; Iveson, K. Art and crime (and other things besides ... ): Conceptualising graffiti in the city. Geogr. Compass 2011, 5, 128-143. [CrossRef]

3. Poon, S.T.F. Street murals as a unique tangible cultural heritage: A case study of artifact value preservation. Int. J. Cult. Creat. Ind. 2016, 4, 48-61.

4. Riggle, N.A. Street art: The transfiguration of the commonplaces. J. Aesthet. Art Crit. 2010, 68, 243-257.

5. Rainer, L. The conservation of outdoor contemporary murals. GCI Newsl. 2004, 18, 4-9.

6. Sánchez Pons, M.; Shank, W.; Fuster López, L. Conservation Issues in Modern and Contemporary Murals; Cambridge Scholars Publishing: New Castle upon Tyne, UK, 2015.

7. Chatzidakis, M. Street art conservation in Athens: Critical conservation in a time of crisis. Stud. Conserv. 2016, 61, 17-23. [CrossRef]

8. Santabárbara, C. Street art conservation: Beyond mural restoration. Opus 2018, 2, 147-162.

9. Macchia, A.; Ruffolo, S.A.; Rivaroli, L.; Malagodi, M.; Licchelli, M.; Rovella, N.; Randazzo, L.; La Russa, M.F. Comparative study of protective coatings for the conservation of urban art. J. Cult. Herit. 2020, 41, 232-237. [CrossRef] 
10. Urquhart, D. The Treatment of Graffiti on Historic Surfaces: Advice on Graffiti Removal Procedures, Anti-graffiti Coatings and Alternative Strategies; Historic Scotland Technical Advice Note S; TCRE Division, Scottish Conservation Bureau, Hist: Edinburgh, UK, 1999; Volume 18.

11. Lubelli, B.; van Hees, R.P.; van de Weert, T.G. The drying behaviour of building materials treated with anti-graffiti. In Hydrophobe $V$, Proceedings of the Fifth International Conference on Water Repellent Treatment of Building Materials, Brussels, Belgium, 15-16 April 2008; Aedificatio Publishers: Freiburg, Germany, 2008; pp. 85-94.

12. Gagné, L. Evaluation of Two Sacrificial Anti-Graffiti Polysaccharide Coatings for the Conservation of Outdoor Contemporary Murals. Master's Thesis, Queen's University Kingston, Kingston, ON, Canada, 2014.

13. Whitford, M.J. Getting Rid of Graffiti; Taylor and Francis: London, UK, 1992.

14. García, O.; Malaga, K. Definition of the procedure to determine the suitability and durability of an anti-graffiti product for application on cultural heritage porous materials. J. Cult. Herit. 2012, 13, 77-82. [CrossRef]

15. Macchia, A.; Mangini, F.; Ruffolo, S.A.; Muzi, M.; Rivaroli, L.; Ricca, M.; La Russa, M.F.; Frezza, F. A novel model to detect the content of inorganic nanoparticles in coatings used for stone protection. Prog. Org. Coat. 2017, 106, 177-185. [CrossRef]

16. Balliana, E.; Ricci, G.; Pesce, C.; Zendri, E. Assessing the value of green conservation for cultural heritage: Positive and critical aspects of already available methodologies. Int. J. Conserv. Sci. 2016, 7, 185-202.

17. Ameta, S.C.; Ameta, R. Green Chemistry, Fundamentals and Applications; Apple Academic Press: New York, NY, USA, 2013.

18. Matlack, A. Introduction to Green Chemistry; CRC press: Boca Raton, FL, USA, 2010.

19. Clarke, S.; Burke, R.J. Occupational Health and Safety; Routledge: London, UK, 2011.

20. Pellis, A.; Byrne, F.P.; Sherwood, J.; Vastano, M.; Comerford, J.W.; Farmer, T.J. Safer bio-based solvents to replace toluene and tetrahydrofuran for the biocatalyzed synthesis of polyesters. Green Chem. 2019, 21, 1686-1694. [CrossRef] [PubMed] 